\title{
Left-Sided Cardiac Valvulitis in Tristetraprolin-Deficient Mice
}

\section{The Role of Tumor Necrosis Factor $\alpha$}

\author{
Sanjukta Ghosh, ${ }^{*}$ Mark J. Hoenerhoff, ${ }^{\dagger}$ \\ Natasha Clayton, ${ }^{\dagger}$ Page Myers, ${ }^{\ddagger}$ \\ Deborah J. Stumpo, ${ }^{*}$ Robert R. Maronpot, ${ }^{\dagger}$ \\ and Perry J. Blackshear ${ }^{\star}$ \\ From the Laboratories of Signal Transduction,* Experimental \\ Pathology, ${ }^{\dagger}$ and the Comparative Medicine Branch, ${ }^{\ddagger}$ National \\ Institute of Environmental Health Sciences, Research Triangle \\ Park, North Carolina; and the Departments of Medicine and \\ Biochemistry, ${ }^{\S}$ Duke University Medical Center, Durham, \\ North Carolina
}

Inflammation may play a role in the etiology of both degenerative and rheumatic cardiac valve diseases. We report here that mice deficient in tristetraprolin (TTP), a protein with known anti-inflammatory functions, develop severe left-sided cardiac valvulitis. TTP is an mRNA binding protein that inhibits inflammation by destabilizing the mRNA encoding tumor necrosis factor $\alpha$ (TNF). This leads in turn to a TNF-excess syndrome characterized by systemic inflammation. Evaluation of hearts from $\mathbf{T T P}^{-/-}$mice demonstrated gross thickening of the mitral and aortic but not the tricuspid or pulmonary valves, accompanied by inflammatory cell infiltrates. To determine whether TNF played a role in the development of this valvulitis, we examined mice deficient in both TNF receptors and in TTP; four of five of these mice exhibited no histological evidence of valvulitis, but one mouse had aortic valve leaflet thickening with a cellular infiltrate. Four additional mice had no external evidence of valvular thickening. Cardiac valves of transgenic mice expressing human TNF developed mild aortic valve leaflet edema without evidence of hypercellularity. Thus, TTP deficiency in mice leads to left-sided cardiac valvulitis with prominent inflammatory cell involvement, due, at least in part, to excess TNF. These findings support the potential involvement of TNF and inflammation in the development of cardiac valve disease in man. (Am J Pathol 2010, 176:1484-1493; DOI: 10.2353/ajpath.2010.090498)
Valvular heart disease (VHD) remains a significant public health concern, with both infectious and noninfectious etiologies. Although the incidence of rheumatic valve disease has declined in developed countries, degenerative VHD remains common in adults over 65 years of age in United States and Europe. ${ }^{1}$ Valve replacement can improve the hemodynamic defects, but at the cost of significant perioperative morbidity and mortality, as well as often requiring long-term anticoagulant treatment. Better knowledge of the etiological mechanisms of non-rheumatic VHD could lead to novel prevention strategies.

Although many forms of VHD have been considered passive degenerative processes, recent studies have suggested the involvement of inflammation in their etiology. ${ }^{2,3}$ For example, non-rheumatic aortic valve stenosis can be accompanied by inflammatory cell infiltrates, and elevated levels of apolipoproteins $B$ and $A^{4}$ and complement factors. ${ }^{5}$ Studies of aortic valve calcification have suggested that early valvular lesions are not simply the consequence of aging, but rather result from active cellular processes that follow the classical response to injury. ${ }^{6}$ Aortic stenosis has been proposed as a surrogate marker for systemic inflammation, ${ }^{7,8}$ although other studies have not found such a link. ${ }^{9}$ Another study reported that increases in an index of systemic inflammation were associated with increased risk of having one or more calcified valves, but the odds ratios were not significant after adjustment for cardiovascular risk factors. ${ }^{10}$ Thus, an unequivocal link between non-rheumatic VHD and systemic inflammation has not yet been established. ${ }^{11}$

Supported by the Intramural Research Program of the NIH, NIEHS.

This work was prepared as part of our official duties. Title 17 U.S.C. 105 provides that "Copyright protection under this title is not available for any work of the United States Government." Title 17 U.S.C. 101 defines a U.S. Government work as a work prepared by a military service member or employee of the U.S. Government as part of that person's official duties.

Accepted for publication November 5, 2009.

Address reprint requests to Perry J. Blackshear, M.D., D.Phil., Box F1-13, National Institute of Environmental Health Sciences, 111 Alexander Drive, Research Triangle Park, NC 27709. E-mail: black009@niehs.nih.gov. 
We have previously described a systemic inflammatory state in mice deficient in tristetraprolin (TTP), a CCCH tandem zinc finger protein. ${ }^{12}$ TTP binds to AU-rich elements within the $3^{\prime}$-untranslated region of mRNAs, including that encoding the pro-inflammatory cytokine tumor necrosis factor $\alpha$ (TNF). Binding of TTP to its target transcript leads to deadenylation and decay of the mRNA. ${ }^{13}$ Conversely, in the absence of TTP, there is a marked increase in the stability of the TNF mRNA, and increased secretion of this cytokine from macrophages and other cells. ${ }^{12}$ This inflammatory phenotype was largely prevented in young TTP ${ }^{-1-}$ mice injected repeatedly with anti-TNF antibodies, and mice deficient in both types of TNF receptors, as well as TTP. ${ }^{14,15}$ Thus, elevated systemic levels of TNF were implicated in the pathogenesis of virtually all aspects of the TTP-deficiency syndrome. Although TNF appears to be the major contributor to the phenotype of the TTP deficiency syndrome, other apparently physiological targets of TTP have been described, eg, granulocyte macrophage-colony stimulated factor, ${ }^{16}$ interleukin $1 \beta,{ }^{17}$ interleukin $10,{ }^{18}$ immediate early response gene $3,{ }^{19} \mathrm{CXCl} 1,{ }^{20}$ and others, and these may well contribute to some aspects of the TTP deficiency phenotype.

Here we present evidence that inflammatory left-sided cardiac valvulitis is a component of the TTP-deficiency syndrome. The valves and adjoining tissue from TTPdeficient mice are markedly thickened, with prominent granulocyte and macrophage cell infiltration, increased collagen synthesis, and neovascularization, resulting in presumed valvular dysfunction and potential cardiac overload. Evaluation of TTP-deficient mice also lacking both TNF receptors strongly implicates elevated TNF as a contributing factor to this valvulitis. These data suggest that TNF, as well as its regulatory protein TTP, may play roles in the pathogenesis of some types of VHD in man.

\section{Materials and Methods}

\section{Mice}

All animal procedures were approved by the NIEHS Animal Care and Use Committee. Male B6.Cg(SJL)-Tg(TNF) (Taconic, model 001006-T-M) ${ }^{21}$ mice were purchased from Taconic Laboratories (Germantown, NY). TTP-deficient mice ${ }^{12}$ had been backcrossed for 17 to 19 generations into the $\mathrm{C} 57 \mathrm{Bl} / 6$ strain, or 9 to 10 generations into the 129SvS6 strain, at the time of the study. TTP/TNFRI/ TNFRII triple knockout (3KO) mice were generated as described. ${ }^{14}$ Mice were routinely monitored for loss of body weight, arthritis and dermatitis. Their bone mineral density and body fat composition were measured using the Piximus Densitometer 2.0 (Lunar Corporation, Madison, $\mathrm{WI}$ ) while anesthetized by 1 to $2 \%$ isofluorane/oxygen (Baxter Healthcare Corporation, Deerfield, IL).

\section{Histology}

Seventeen pairs of matched littermate wild-type and $\mathrm{TTP}^{-1-}$ mice were used for cardiac histology studies, which included thirteen 129SvS6 pairs (six male pairs and seven female pairs), and four C57BI/6 pairs (two male pairs and two female pairs). Mice were euthanized with $\mathrm{CO}_{2}$, and the hearts were fixed by immersion in $10 \%$ neutral buffered formalin overnight at $4^{\circ} \mathrm{C}$. The hearts were then embedded in paraffin and sectioned, or embedded in optimal cutting temperature compound (Tissue Tek, Sakura Finetek U.S.A. Inc., Torrence, CA) and frozen. Sections of interest were stained with H\&E, Alcian Blue-Periodic Acid Schiff's Reagent ( $\mathrm{pH}$ 2.5), Masson's Trichrome, Verhoeff-Van Gieson Elastic stain, or Von Kossa stain using standard techniques, or immunostained as described below.

\section{Immunohistochemistry}

Formalin-fixed, paraffin-embedded sections were incubated with antibodies against Ki-67 (TEC3) (Dako Corporation, Carpinteria, CA), F4/80 (Caltag Laboratories, Burlingame, CA), and Ly6G (BD Biosciences, San Jose, CA), using standardized immunohistochemistry procedures, with suitable positive control tissue for each case, with normal rat serum (Jackson Immunoresearch Laboratories, PA) as a negative control. Neutrophil differentiation antigen (clone 7/4), ${ }^{22}$ microsialin (FA-11), ${ }^{23}$ type $3 \mathrm{com}$ plement receptor (clone 5C6), ${ }^{24}$ mannose receptor, ${ }^{25}$ macrophage receptor with collagenous structure, MARCO (ED31), ${ }^{26}$ sialoadhesin (SER-4), ${ }^{27} \mathrm{~T}$ cell marker (CD3), and activated B cell marker (CD45R-B220), were detected using frozen sections that were fixed with acetone, as described earlier. ${ }^{24}$ Von Willebrand factor was detected on formalin-fixed, paraffin-embedded sections using the Rabbit Elite kit (Vector Laboratories, Burlingame, CA). In general, endogenous peroxidase was quenched and slides were rinsed in Automation buffer (Government Scientific Source, Reston, VA), blocked with 5\% (v/v) normal rabbit serum (Vector Laboratories, Burlingame, CA), or normal goat serum (Jackson Immunoresearch Laboratories) for 20 minutes at room temperature, and then with Avidin/Biotin blocking agent (Avidin/Biotin Blocking kit, Vector Laboratories) for 15 minutes at room temperature. After incubation with primary antibody for 1 hour, and suitable washing, slides were incubated with the appropriate biotinylated secondary antibody for 30 minutes, rinsed multiple times with Automation Buffer, and then incubated with Streptavidin Peroxidase SS label antibody (Biogenex, San Ramon, CA) for 30 minutes. The final development was done using Dako DAB Chromagen for 6 minutes in the dark.

\section{Echocardiography}

Echocardiographic studies were performed using the $\mathrm{Vi}$ sualsonics Vevo 660 V1.3.8 B41 High-Resolution Imaging System (Visualsonics, Canada). Transthoracic two-dimensional M-mode and Doppler echocardiography was performed using a $35 \mathrm{MHz}$ Doppler transducer (Visualsonics model RMV707) on 13 pairs of wild-type and $\mathrm{TTP}^{-1-}$ animals under light anesthesia as described above, with the animals supine on a temperature-con- 
trolled printed circuit platform. Recordings were made after at least seven minutes of anesthesia, with heart rates between 330 and 480 beats per minute. Two-dimensional paraxial short axis views of the left ventricle at the level of the papillary muscles were obtained for internal dimensions at end-diastole and end-systole, and off-line measurements from M-mode recordings were performed in at least three cardiac cycles per animal. Doppler measurements of the left ventricle were made at five different points within the chamber per animal, and left ventricular contraction time, relaxation time, and ejection time were measured. Offline measurements of percent left ventricular fractional shortening and left ventricular ejection fraction were also performed.

\section{Dissection of Valves and RNA Isolation}

Ventricular tissue was finely diced and immediately collected into RNA Later Buffer (Ambion). RNA was extracted using the Qiagen RNeasy Miniprep Kit (Qiagen, Santa Clarita, CA). Laser capture microdissection was performed as follows: fresh-frozen hearts were cut into $8-\mu \mathrm{m}$ coronal sections and collected onto polyethylene terephthalate foil slides (MMI CellCut, Glattbrugg, Switzerland) (MMI). Valves were dissected using a solid state cutting laser beam (UV $355 \mathrm{~nm}$ at $72 \%$ to $77 \%$ power) and collected directly onto adhesive caps of tubes (MMI) for RNA isolation using the Picopure RNA isolation kit (Molecular Devices, Sunnyvale CA).

\section{Real-Time PCR}

DNA was digested from the RNA samples following the manufacturer's instructions (Applied Biosystems $[A B I]$, Foster City, CA), and then RNA was converted into CDNA using the High Capacity cDNA Archive kit (ABI). 10 ng of the resulting CDNA was used per reaction for TaqMan real time PCR in the ABI Prism, 7900HT Sequence Detector System (ABI). Pre-designed primer-probe sets for TNF, TTP, and glyceraldehyde-3-phosphate dehydrogenase transcripts were purchased from ABI. Results for the TNF and TTP transcripts were normalized to those of GAPDH transcripts.

\section{Statistical Analysis}

Differences between the data sets were analyzed for statistical significance using one or two-tailed Student's $t$-test. $P$ values of less than or equal to 0.05 were considered significant.

\section{Results}

\section{TTP Deficiency Is Associated with Left-Sided Cardiac Valvulitis in Mice}

$\mathrm{TTP}^{-1-}(\mathrm{KO})$ mice exhibit joint swelling and weight loss, generally beginning at 6 to 12 weeks of age. We evaluated these mice for a potential cardiac phenotype at
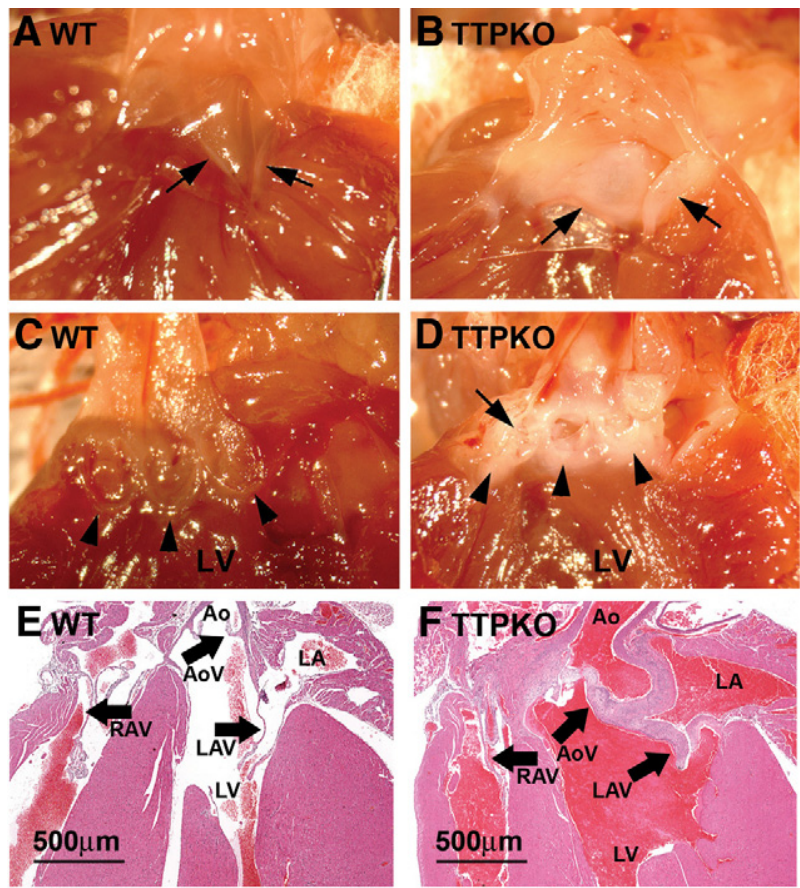

Figure 1. Valvulitis in TTP ${ }^{-/-}$mice. A-D: Gross examination of the aortic and mitral valves from wild-type (WT) control and TTP KO hearts. A, C: Normal appearing mitral (A) and aortic (C) valves in wild-type controls. Note the thin and translucent nature of the two mitral valve leaflets (A, arrows $20 \mathrm{X})$ and the three cusps of the aortic valve $(\mathbf{C}$, arrowheads, $\times 20)$. B, D: Abnormal mitral and aortic valves in TTP KO mice. There is marked thickening and fibrosis of the mitral valve $(\mathbf{B}$, arrows, $\times 20)$ causing malformation and partial fusion to the underlying endocardium. The aortic valve is markedly thickened, irregular, and fibrotic (D, arrowheads, $\times 20)$, with cusp fusion to the adjacent endocardial surface (arrow). E and F: Coronal sections of wild-type and TTP KO hearts stained with H\&E. The left panel is a section through a wild-type heart showing normal valves. The right panel is a section through a TTP KO heart, showing thickening and cellular infiltration at and around the aortic valve (AoV) and the left atrioventricular valve (LAV), but an apparently normal right atrioventricular valve (RAV). LA, left atrium; $\mathrm{LV}$, left ventricle; Ao, aorta.

various ages, with age-matched littermate wild-type mice as controls.

All TTP KO mice evaluated exhibited aortic and left atrioventricular valvulitis based on histomorphological analysis (Figure 1, Table 1). This was evident in mice as young as 7 weeks, and showed no significant gender bias (Table 1). The basic pattern of valvulitis was essentially similar in both $129 \mathrm{SvS} 6$ and B6 strains of mice. In five TTP KO mice evaluated at an average of 23 weeks of age, the gross morphology of the mitral and aortic valves was markedly altered compared with valves from agematched controls (Figure 1, A-D). The leaflets from the mitral and aortic valves were markedly fibrotic and grossly thickened to approximately 10 to 20 times normal in all of the $\mathrm{KO}$ mice examined, and there was obvious whitish discoloration of the leaflets (Figure 1, A-D). The valve leaflets in the $\mathrm{KO}$ mice were often fused to the underlying endocardium and to each other. In contrast, external examination of mitral and aortic valves from four TTP/TNFR1/TNFR2 "triple KO" mice at 24 to 25 weeks of age (see below) revealed normal valve morphology in every case (data not shown). In all of the TTP KO mice evaluated, the right atrioventricular and pulmonary valves appeared normal, both by external morphology (not 
Table 1. Physical and Echocardiographic Data from Wild-Type and $\mathrm{TTP}^{-1-}$ Mice

\begin{tabular}{|c|c|c|c|c|}
\hline & \multicolumn{2}{|c|}{ Female } & \multicolumn{2}{|c|}{ Male } \\
\hline & $\begin{array}{l}\text { Wild-type } \\
(n=7)\end{array}$ & $\begin{array}{l}\mathrm{TTP}^{-1-} \\
(n=7)\end{array}$ & $\begin{array}{l}\text { Wild-type } \\
(n=6)\end{array}$ & $\begin{array}{l}\mathrm{TTP}^{-1-} \\
n=6)\end{array}$ \\
\hline \multicolumn{5}{|l|}{ Gross morphometry } \\
\hline Body weight $(\mathrm{g})$ & $31 \pm 2.8$ & $18.23 \pm 3.11^{\ddagger}$ & $27.21 \pm 3$ & $17.88 \pm 1.89^{\ddagger}$ \\
\hline Bone density $\left(\mathrm{g} / \mathrm{cm}^{2}\right)$ & $0.0567 \pm 0.03$ & $0.043 \pm 0.007^{\ddagger}$ & $0.053 \pm 0.006$ & $0.043 \pm 0.003^{\ddagger}$ \\
\hline Body fat $(\%)$ & $25.24 \pm 0.99$ & $15.16 \pm 0.076^{\ddagger}$ & $31.95 \pm 3.11$ & $15.15 \pm 0.871^{\ddagger}$ \\
\hline \multicolumn{5}{|c|}{ Microscopic valve thickness measurements $\$$} \\
\hline LAV thickness $(\mu)$ & $27.33 \pm 1.44$ & $119.33 \pm 6.94^{*}$ & $32.66 \pm 3.2$ & $106.66 \pm 4.47^{*}$ \\
\hline AoV thickness $(\mu)$ & $28.5 \pm 1.02$ & $148 \pm 9.71^{*}$ & $31 \pm 1.93$ & $155 \pm 7.7^{\star}$ \\
\hline \multicolumn{5}{|c|}{ Echocardiographic measurements } \\
\hline Average heart rate (bpm) & 370.67 & 396.44 & 365.2 & 346.42 \\
\hline LVIDd (mm) & $3.64 \pm 0.108$ & $4.25 \pm 0.2^{\dagger}$ & $3.71 \pm 0.42$ & $4.46 \pm 0.24^{\dagger}$ \\
\hline LVIDs (mm) & $2.56 \pm 0.138$ & $2.96 \pm 0.6^{\dagger}$ & $2.74 \pm 0.08$ & $3.39 \pm 0.47^{\dagger}$ \\
\hline LVCT (msec) & $19 \pm 2.06$ & $24 \pm 5.5$ & $22 \pm 3.54$ & $20.25 \pm 1.06$ \\
\hline LVRT (msec) & $22 \pm 1.57$ & $29 \pm 1.76$ & $25 \pm 3.91$ & $30.04 \pm 4.74$ \\
\hline LVET (msec) & $55 \pm 2.52$ & $69.6 \pm 3.04$ & $58.78 \pm 3.32$ & $53.14 \pm 6.13$ \\
\hline LV \%EF & $56.95 \pm 3.13$ & $58.77 \pm 2.57$ & $51.29 \pm 3.83$ & $48.03 \pm 1.64$ \\
\hline LV \%FS & $30.3 \pm 1.99$ & $32.65 \pm 2.87$ & $30.34 \pm 2.64$ & $26.5 \pm 1.04$ \\
\hline
\end{tabular}

The data shown are from 13 ( 6 male, 7 female) 129SvS6 TTP $^{-1-}$ mice and an equivalent number of sex-matched littermate wild-type mice, unless stated otherwise. The mean age of these mice was $24.4 \pm 1.2$ weeks $( \pm$ SEM); $n=3$ per group for these measurements.

${ }^{*} P<0.05 ;{ }^{\dagger} P<0.01 ;{ }^{\ddagger} P<0.001$, as determined by Student's two tailed $t$-test.

$\S L A V$, left atrioventricular valve; AoV, aortic valve; LVIDd, left ventricular internal diastolic diameter; LVIDs, left ventricular internal systolic diameter LVCT, left ventricular contraction time; LVRT, left ventricular relaxation time; LVET, left ventricular ejection time; EF, left ventricular ejection fraction; FS, fractional shortening.

shown) and histologically (Figure 1, E and F). A few of the TTP KO mice also had minimal multifocal myocardial lesions characterized by mononuclear infiltrates (data not shown), while none of the wild-type counterparts showed either of the above features.

\section{Histomorphological Characterization of the Cardiac Valves in TTP KO Mice}

We used specific histological staining to determine whether the inflamed valves were characterized by myxomatous thickening, calcification, or cellular infiltration. Alcian Blue-PAS staining of the tissue demonstrated elevated levels of hyaluronic acid and acidic mucopolysaccharides in the thickened left atrioventricular and aortic valve leaflets and the bases of these valves in the TTP KO mice, indicating the presence of chronic inflammation (Figure 2A). There was also increased staining of mature collagen in the TTP KO valves (Figure 2B). Von Kossa staining revealed no evidence of mineralization in these valves (data not shown). Interestingly, the thickened valves also exhibited evidence for neovascularization, as demonstrated by immunostaining for Von Willebrandt factor, indicating the involvement of an endothelial activation signal (Figure 2C). Elastin staining demonstrated disrupted and disorganized elastic fibers at the bases of the valves (Figure 2D), which indicate possible functional impairment of the valves due to inflammation.

H\&E staining revealed marked mononuclear infiltration in the valves (Figure 3B, upper panel). Many of these cells were actively dividing, as indicated by the expression of the proliferation marker Ki-67 (Figure 3A, upper panel). The infiltrating cells were immunoreactive for the CD45 cell surface marker (Figure 3A, lower panel), indicating their leukocytic nature; normal valves rarely con- tain leukocytes ${ }^{11}$ (Figure 3A). Frozen sections of aortic valves were analyzed for specific cell surface markers. Monoclonal antibody clone $7 / 4^{22}$ was used to detect neutrophil differentiation antigen (Figure 3B), and demonstrated robust positive immunostaining for neutrophils in the TTP KO valves. Similar results were found with a monoclonal antibody to Ly6G, a neutrophil surface antigen (data not shown). Monocytes/macrophages, detected via staining for microsialin ${ }^{23,28}$ using the monoclonal antibody clone FA11 (Figure 3B), were also highly represented in the knockout but not control valves. Monoclonal antibody clone 5C6, directed at the type $3 \mathrm{com}$ plement receptor, ${ }^{24}$ stains for neutrophils, monocytes, and macrophages infiltrating tissue in response to an inflammatory stimulus; the data shown in Figure 3B demonstrate high levels of positive staining for this marker in the $\mathrm{KO}$ valves. We also observed robust staining using antibodies directed at the macrophage antigen F4/80 and the mannose receptor, ${ }^{25}$ but not the lectin-like SER-4 antigen, ${ }^{27}$ which is expressed on resting bone marrow macrophages (data not shown). Likewise, the macrophages were not immunoreactive to the macrophage scavenger receptor MARCO (data not shown), whose expression is elevated on the surface of bone marrow. spleen and lung macrophage on microbial challenge. ${ }^{26}$ The wild-type valve tissues were nonreactive to all of the above-mentioned antibodies, indicating the essential absence of these immune cells. Finally, we did not detect either T lymphocytes (using an antibody to CD3) or activated B lymphocytes (using an antibody to B220) in either the wild-type or TTP KO valves (data not shown).

Transthoracic echocardiographic examination of TTP $\mathrm{KO}$ mice at an average age of 24 weeks demonstrated significant left ventricular enlargement at end-systolic and end-diastolic phases (Figure 4; Table 1), compatible 


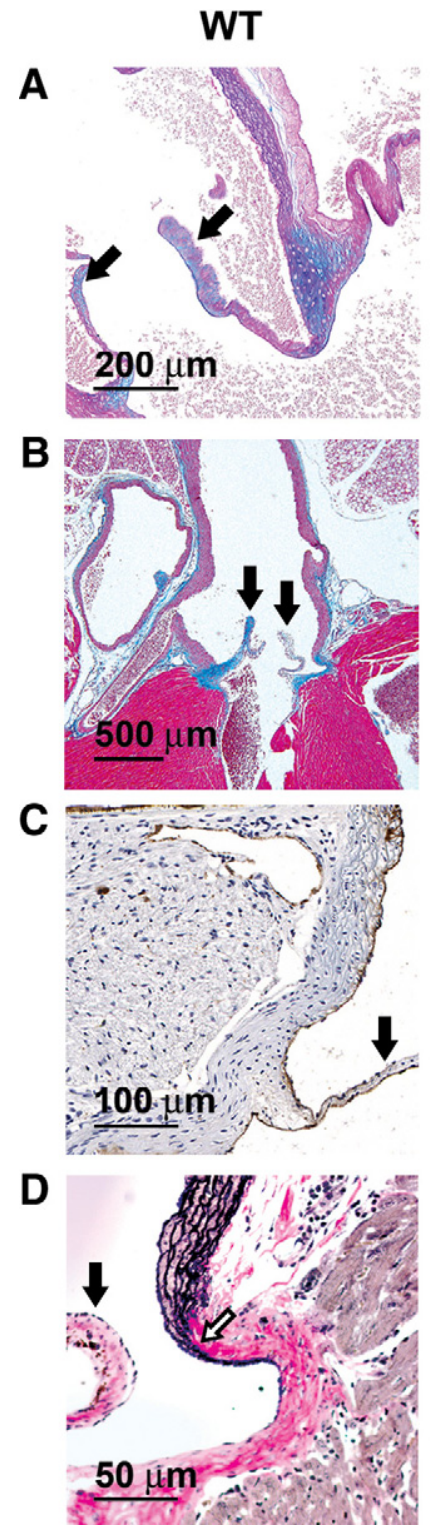

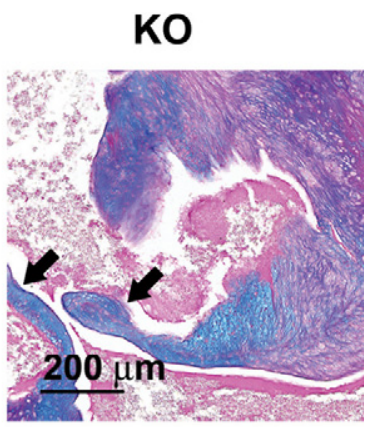
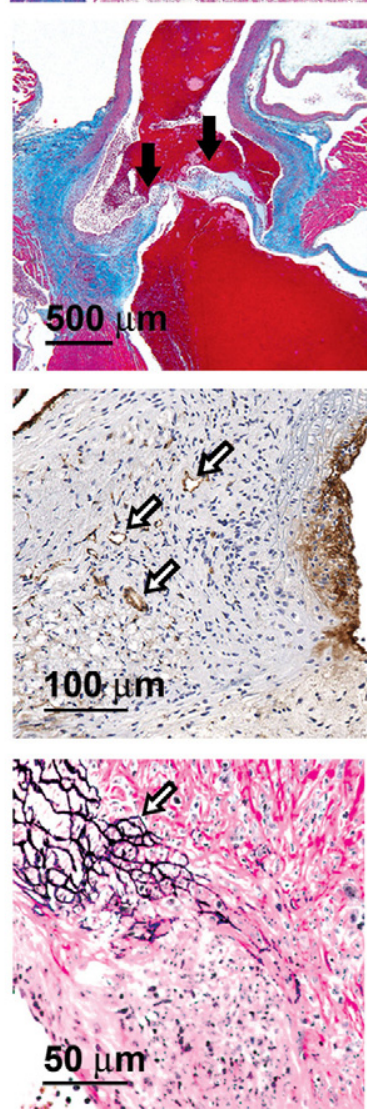

Figure 2. Histomorphometric characterization of wild-type (WT) and $\mathrm{TTP}^{-1-}$ valves. Coronal sections of hearts from representative age and gender-matched wild-type and TTP-KO mice were stained with the following histological stains. A: Alcian Blue-PAS ( $\mathrm{pH} 2.5$ ), which stains hyaluronic acid and sialomucins blue and polysaccharides and neutral mucosubstances magenta to red. The arrows point to the increased blue stained area in the $\mathrm{TTP}^{-/-}$sections (right) compared with the wild-type (left), indicating an increase in acidic mycosubstances in the tissue, generally thought to be due to inflammation. B: Masson's Trichrome, which stains cytoplasm, keratin, muscle fibers and intracellular fibers red, nuclei black and collagen blue. The $\mathrm{TTP}^{-/-}$valve (right) shows increased positive staining for collagen. C: immunohistochemical staining for Von Willebrandt Factor, which detects endothelial lining (brown). The hollow arrows point toward neovascularization at the base of the aortic valve in the TTP ${ }^{-1-}$ sections (right), which is lacking in the wild-type sections (left). D: Verhoeff-Van Gieson stain for elastic fibers. Under these staining conditions, elastic fibers are stained dark brown, and collagen bundles pink. Disruption of the elastin fibers is present in the TTP-KO valves shown by the hollow arrows (right), while these fibers are intact in wild-type valves, with the corresponding area indicated by the hollow arrow (left). Solid arrows indicate aortic valve leaflets.

with left ventricular overload. However, the left ventricular fractional shortening and ejection fraction percentages were not significantly different between the TTP KO and control groups. Left atrial enlargement was also observed
A

Ki67
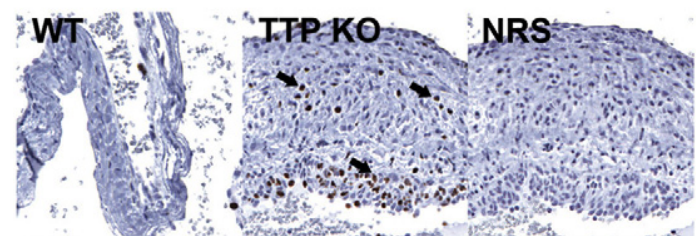

CD45

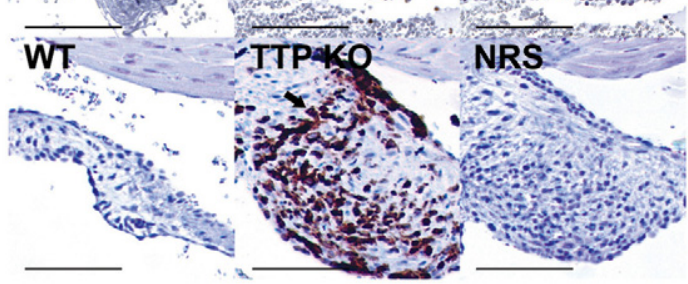

B

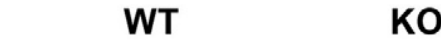

H\&E

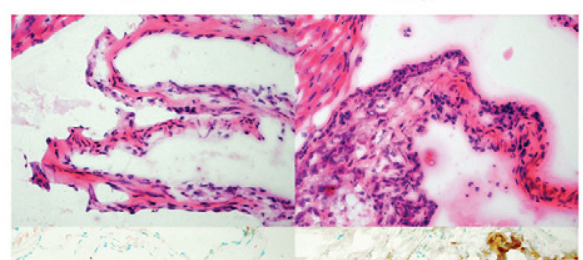

$7 / 4$

FA-11

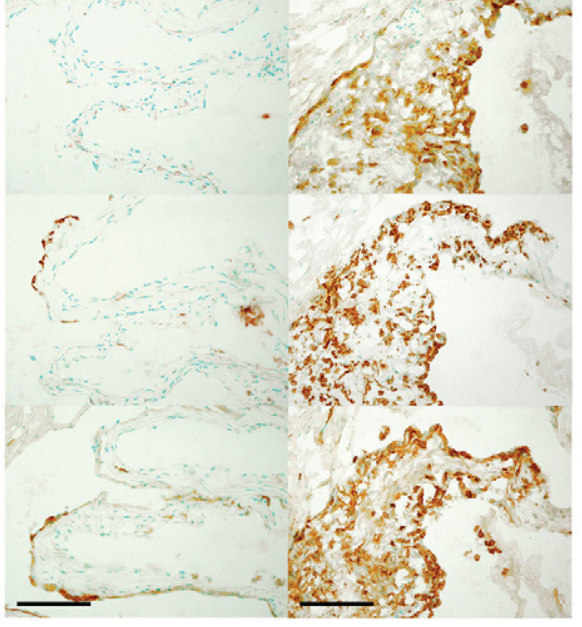

Figure 3. Immunohistochemical staining of TTP-KO valves. A: Upper panel: Sections of mitral valves from wild-type (WT) and TTP-KO animals were stained for the proliferation marker Ki-67. The arrows point to the proliferating cells. Lower panel: Sections from left atrioventricular valve leaflets were stained for CD 45, a pan-leukocyte marker. NRS, normal rat serum used in place of the primary antibody as negative control for immunostaining. Scale bars $=100 \mu \mathrm{m}$ B: Frozen sections of aortic valves were analyzed for specific cell surface markers, as indicated to the side of each panel. The uppermost panel shows H\&E staining of neighboring sections. Monoclonal antibody clone 7/4 was used to identify neutrophil differentiation antigen; clone FA-11 stained for microsialin, expressed on the surface of macrophages; and antibody 5C6 stained for the type 3 complement receptor, characteristic of granulocytes, monocytes, and tissue infiltrating macrophages. Scale bar $=100 \mu \mathrm{m}$.

in the TTP KO mice (data not shown). These results suggested possible functional impairment of the left atrioventricular and aortic valves in the $\mathrm{TTP}^{-1-}$ mice.

\section{Role of TNF in the Valve Disease Pathogenesis}

The pathological changes observed in the TTP KO valves, including increased mature collagen and inflammation, suggested the possibility that chronically elevated local TNF levels could be associated with the pathogenesis of this aspect of the TTP KO phenotype. TNF mRNA levels were 


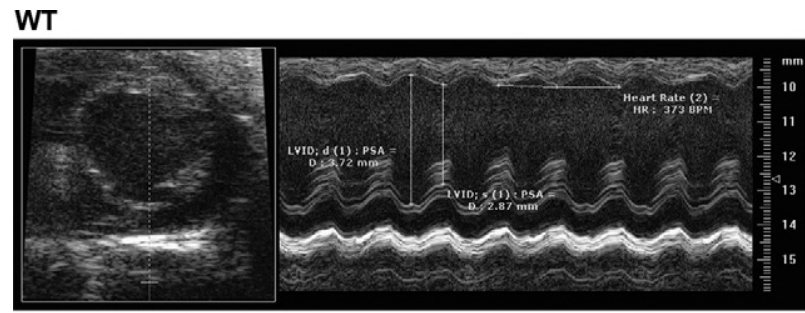

\section{TTPKO}

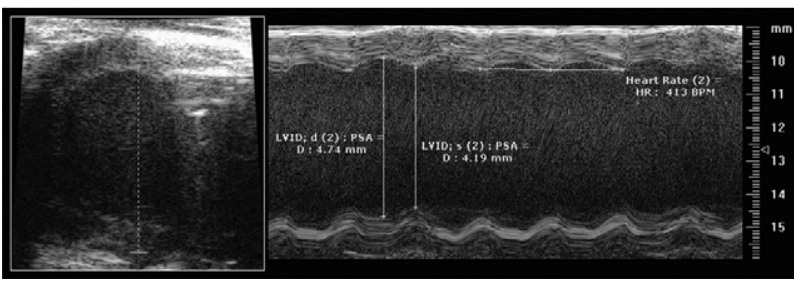

Figure 4. Ultrasonographic images of wild-type (WT) and $\mathrm{TTP}^{-/-}$hearts M-mode recordings were made of the paraxial short axis at the level of papillary muscles, showing the end-diastolic and end-systolic dimensions. Detectable enlargement of the left ventricular compartment is evident in the TTP $^{-1-}$ mouse (male, aged 26 weeks) compared with the age-and gendermatched wild-type control. HR, heart rate; LVIDd, left ventricular diastolic internal diameter; LVIDs, left ventricular systolic internal diameter.

increased three-fold in the left ventricular tissue from the TTP KO mice, as compared with the right ventricles, while the differences between the two compartments in the wildtype mice were insignificant (Table 2). Also, there was a sixfold increase in TNF mRNA levels in affected TTP KO valve leaflets compared with their wild-type counterparts (Table 2). Since these measurements were of TNF mRNA rather than protein, they suggest that the excess TNF in the TTP KO hearts was locally produced, presumably by infiltrating leukocytes.

\section{Cardiac Phenotype of TTP/TNFRI/TNFRII ("Triple KO") Mice}

To further understand the role of TNF in the valve pathology, we examined the valves of mice that lacked TTP and both TNF receptors ("triple KO mice"). ${ }^{14}$ These animals appear essentially normal when young but can develop bone marrow myeloid hyperplasia late in life. ${ }^{14}$ The mice evaluated histologically in this study were between 48 and 50 weeks of age, and exhibited decreased average body weight, from $38 \pm 4 \mathrm{~g}$ in the age and gender matched wild-type control mice to $25 \pm 3 \mathrm{~g}$ in the triple KO mice (data not shown), suggesting that the mice used in this study had developed the late-onset TTP deficiency phenotype seen in these triple $\mathrm{KO}$ mice after about 20 weeks of age. ${ }^{14}$ Gross examination of four triple KO mice at 24 to 25 weeks of age revealed no detectable external abnormalities in any of the four valves (not shown). Histologically, the mitral and right atrioventricular valves appeared normal in all five triple KO mice (data not shown). Four of the five animals had histologically normal aortic valves (Figure 5B), marked by absence of valve thickening, similar to valves from their wild-type controls (Figure $5 \mathrm{~A}$ ), with the exception of occasional small foci of mononuclear cells at the root of the aorta (Figure 5C). However, one of five triple $\mathrm{KO}$ mice exhibited moderate thickening of the aortic valve that was detectable histologically, accompanied by mononuclear cell infiltration. These lesions were not seen in the control littermate mice.

\section{Cardiac Phenotype in Mice Overexpressing Transgenic Human TNF}

We also examined mice that overexpressed transgenic human $\mathrm{TNF}^{21}$ to determine whether chronically elevated systemic TNF was sufficient to cause the left-sided valvulitis. It should be noted that the source of the TNF in these mice is thought be poorly characterized mesenchymal cells, not macrophages, with the lack of macrophage expression implied by the lack of response of the TNF transgene to lipopolysaccharide. ${ }^{17-20,29}$ In the present study, these mice $(n=4)$ were between 19 and 21 weeks of age at the time of evaluation, and were beginning to exhibit joint swelling. At this point they did not exhibit loss of body weight or body fat, characteristic of the TNF excess cachectic phenotype (data not shown). Mitral and tricuspid valves appeared histologically normal in each mouse of this group (data not shown). Sections from the aortic valves revealed mild edema and myxomatous thickening of the valve leaflets (Figure 6, A and B), suggesting that the systemic TNF excess could lead to these processes. However, there was no evidence of mononuclear cell infiltration in the transgenic mouse valves, in striking contrast to the TTP-deficient mice. These data suggest that systemic TNF overexpression may be one contributing factor leading to left-sided cardiac valvulopathy, but may not be solely responsible for the entire pathological spectrum found in the valves from the TTP KO mice.

\section{Discussion}

The major finding of this study is that TTP deficiency is associated with left-sided cardiac valvular inflammation. The inflammation was characterized by gross thickening

Table 2. TNF mRNA Levels in Wild-Type and TTP-KO Mouse Hearts

\begin{tabular}{lcccc} 
& Right ventricle & Left ventricle & Right AV valves & Left AV and Ao valves \\
\hline Wild-type & $0.81 \pm 0.10$ & $1.01 \pm 0.89$ & $0.97 \pm 0.10$ & $1.07 \pm 0.10$ \\
TTP $^{-l-}$ & $0.85 \pm 0.12$ & $2.91 \pm 0.48$ & $0.99 \pm 0.33$ & $6.12 \pm 1.16^{\star}$ \\
\hline
\end{tabular}

Total cellular RNA was extracted from excised ventricular tissue or from tissue isolated from cardiac valves using laser capture microdissection. It was reverse transcribed, and $10 \mathrm{ng}$ of the resulting CDNA was used for real-time PCR detection of TNF mRNA levels. Values were normalized against GAPDH mRNA levels, and expressed as mean fold change \pm SEM, relative to the expression level in one right ventricle sample (for the ventricle comparison) or one right atrioventricular (AV) valve (for the valve comparison), which were set at a value of $1 . n=3$ per group.

${ }^{\star} P<0.05$ compared with the mean from wild-type controls, using one-tailed Student's $t$-test. 

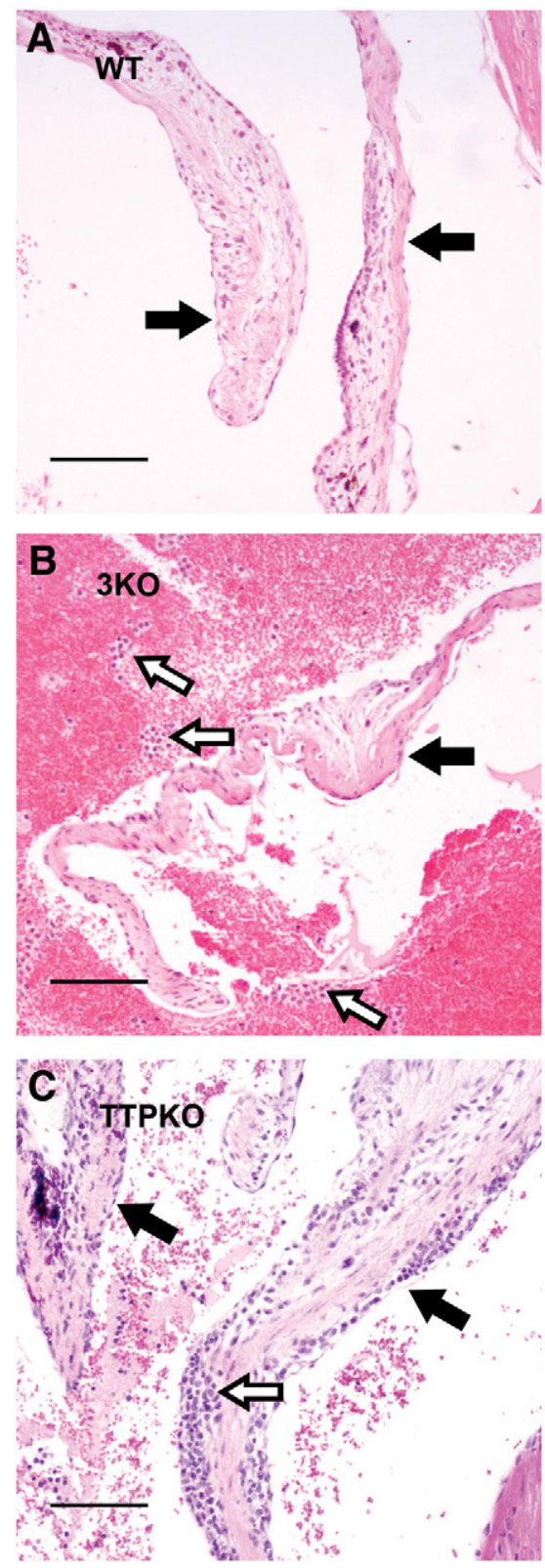

Figure 5. Valve pathology in a triple KO mouse. Representative H\&E stained sections of atrioventricular valves from a wild-type (WT) control mouse (A), and a triple KO mouse (B). Hollow arrows point to granulocytic clusters in the heart tissue with a marked absence of inflammatory cells in the valve leaflet, which is indicated by solid arrow; and a TTP-KO mouse (C), showing inflammatory cell infiltrates (hollow arrow) in the valve leaflet (solid arrow). All three mice described here were 50 weeks old. Scale bars $=100 \mu \mathrm{m}$. Solid arrows indicate left atrioventricular valve leaflets.

and discoloration of mitral and aortic valve leaflets on external examination. Histologically, these valves exhibited monocytic and granulocytic cell infiltration, with apparent absence of lymphocytes, as well as other sequelae of inflammation such as valve thickening, disruption of elastic fibers, myxomatosis, collagen deposition, and neovascularization. The lesion was seen with TTP deficiency in both the C57BI/6 and 129SvS6 backgrounds. These histological findings largely were prevented in four of five mice lacking both types of TNF receptor in addition to TTP, and the external morpholog-
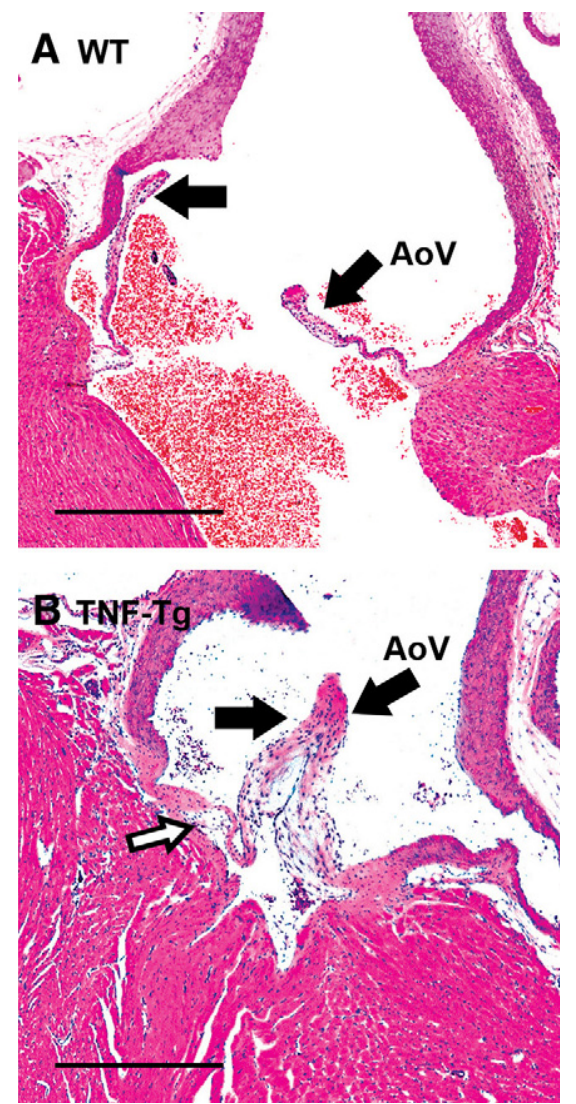

Figure 6. Valve pathology in TNF overexpressing transgenic mice. H\&Estained sections showing an aortic valve of a wild-type (WT) control mouse with a normal valve (A), and an age- and gender-matched TNF transgenic mouse (B) at 21 weeks of age, showing slight myxomatous thickening and edema of the aortic valve. Scale bar $=500 \mu \mathrm{m}$.

ical changes were prevented in all four of a separate group of these "triple KO" mice; however, the presence of mild valve leaflet thickening and cellular infiltration in one of these triple $\mathrm{KO}$ mice raises the possibility that the absence of TTP may play a role in valve inflammation that is independent of its effects on TNF mRNA stability, perhaps involving one of its other recently identified transcript targets. ${ }^{16-20}$ These data identify a previously unreported characteristic of the TTP deficiency syndrome, one that is severe enough to have led to, or at least contributed to, the early deaths of mice with this syndrome.

It is possible that systemic elevation of TNF by itself is not sufficient to cause valvulitis similar to that seen here, since mice expressing transgenic human TNF exhibited only mild thickening of the aortic leaflets, without cellular infiltration. Systemic levels of TNF may well be different in these two mouse models, and the cellular sources are almost certainly different, with transgenic TNF probably not being secreted by macrophages in this mouse. ${ }^{29}$ Similarly, macrophages were probably not the source of the transgenic TNF secretion in a model of cardiac-specific TNF overproduction, ${ }^{30,31}$ and no valvular abnormalities were seen in this model (Barry London, personal communication). Nonetheless, a major role for TNF in the development of the valvulitis phenotype in the $\mathrm{TTP}^{-1-}$ 
mice was demonstrated by the marked attenuation of the valve pathology that was observed in the triple $\mathrm{KO}$ mice. Taken together, our results are compatible with a model in which macrophage and granulocytic cell infiltration into the valves is an early event, leading to local TNF secretion by these cells, followed in turn by other consequences of inflammation. This proposed sequence of events will have to be demonstrated by careful time course studies, perhaps using an inducible CRE-Lox system to remove TTP acutely in the adult mouse, or by doing an experiment in which repeated injections of antibodies to TNF are suddenly withdrawn, leading to rapid development of the TTP deficiency phenotype. ${ }^{12}$

Several other mouse models of TNF overexpression have been investigated, as noted above, but to our knowledge cardiac valvular involvement has not been reported. In addition to the two mouse models mentioned above, another line of transgenic mice with cardiac-restricted overexpression of TNF developed left ventricular hypertrophy. ${ }^{32}$ Cardiac myocyte apoptosis was also described in those mice, ${ }^{33}$ but was not apparent in our model. Probably the most relevant model is a strain of mice engineered to lack the AU-rich region (ARE) of the $3^{\prime}$ untranslated region of TNF mRNA (TNF ${ }^{\triangle A R E}$ ), which exhibit overexpression of the TNF transcript and protein from normal cellular sources, and resemble a more severe version of the TTP KO model. ${ }^{34}$ However, to our knowledge valve pathology has not been reported in these mice. In addition to transgenic models, other mouse models have achieved chronic systemic TNF elevations with repeated TNF injections; however, to our knowledge, these studies did not address heart valve pathology.$^{35-37}$ Recently, genetic abrogation of TAX1BP, a protein that regulates nuclear factor-kappa $\mathrm{B}$ activity, a component of the TNF-induced pathway of inflammation, led to the age-dependent development of inflammatory cardiac valvulitis in mice. ${ }^{38}$ However, this was not limited to the left-sided valves, nor were the infiltrates predominantly myeloid, as observed in the TTP KO mice.

An interesting aspect of the TTP KO phenotype is that it targeted the left cardiac valves while apparently completely sparing the right-sided valves. The greater hemodynamic load in the left cardiac chambers is a likely candidate factor for this differential effect, as seen in other forms of left-sided cardiac valvulitis. ${ }^{11,39,40}$ One could postulate that lack of TTP results in abnormally exaggerated local inflammatory responses to minor insults, which would be greater in the left side of the heart due to its chronic exposure to markedly higher hemodynamic pressures. Systemic hypertension could well contribute to this process, but this has not been examined in the TTP KO mice. Although the functional impairment of the mitral and aortic valves has not been documented in detail in this study, it seems very likely, given the extent of the pathology. We found relative enlargement of both the left ventricular and atrial chambers, suggesting volume overload. Nonetheless, we cannot rule out a possible contribution of elevated levels of TNF in the ventricular myocardium as contributing to the compromised myocardial function.
Cardiac valve disease has been reported in a number of human diseases that can be described as "TNF-excess diseases," as defined by their responsiveness to anti-TNF therapies. ${ }^{41-44}$ These include rheumatoid heart disease, ${ }^{45,46}$ Behcet's disease, ${ }^{47}$ Crohn's disease, ${ }^{48} \mathrm{Ka}$ wasaki's disease, ${ }^{49}$ Wegener's granulomatosis, ${ }^{50}$ and Reiter's syndrome. ${ }^{51,52}$ In rheumatoid arthritis, granulomatous involvement has been noted in the aortic and mitral cusps. ${ }^{53}$ In Reiter's syndrome, severe giant cell valvulitis has been reported. ${ }^{52}$ Some patients with $\mathrm{Ka}$ wasaki's disease had severely damaged aortic and mitral valves with lymphocytic and monocytic infiltrates. ${ }^{54}$ In post-Streptococcal rheumatic valve disease, ${ }^{46,55}$ myosin cross-reactive T-lymphocytes are thought to play a significant role in the initiation and infiltration of the inflammatory valvular lesions. In contrast to these findings in man, our model exhibited neither $T$ nor B lymphocyte involvement in the affected valves, nor granulomas, but rather activated macrophages and neutrophils. Thus, the valvular phenotype found in the TTP ${ }^{-1-}$ mice does not closely resemble those found in human "TNF excess diseases." Instead, it is interesting to speculate that this type of TTP/TNF-dependent left-sided valvular inflammation might be a component of the still unknown process leading to human idiopathic valve disease, in which inflammation is increasingly thought to play a pathogenetic role.

\section{Acknowledgments}

We acknowledge Dr. Rashmi Lahiri and Dr. Siamon Gordon for insightful discussions and Dr. Joy Crowther, Dr. David Malarkey, and Dr. Dori Germolec for carefully reading the manuscript. Special thanks to Beth Mahler, Patricia Stockton, Elizabeth Ney, Norris Flagler, and Liz Darley for technical assistance.

\section{References}

1. Nkomo VT, Gardin JM, Skelton TN, Gottdiener JS, Scott CG Enriquez-Sarano M: Burden of valvular heart diseases: a populationbased study. Lancet 2006, 368:1005-1011

2. Rajamannan NM, Nealis TB, Subramaniam M, Pandya S, Stock SR, Ignatiev CI, Sebo TJ, Rosengart TK, Edwards WD, McCarthy PM, Bonow RO, Spelsberg TC: Calcified rheumatic valve neoangiogenesis is associated with vascular endothelial growth factor expression and osteoblast-like bone formation. Circulation 2005, 111:3296-3301

3. Dellegrottaglie S, Sanz J, Rajagopalan S: Molecular determinants of vascular calcification: a bench to bedside view. Curr Mol Med 2006 , 6:515-524

4. Wallby L, Steffensen T, Broqvist M: Role of inflammation in nonrheumatic, regurgitant heart valve disease. A comparative, descriptive study regarding apolipoproteins and inflammatory cells in nonrheumatic heart valve disease. Cardiovasc Pathol 2007, 16:171-178

5. Helske S, Oksjoki R, Lindstedt KA, Lommi J, Turto H, Werkkala K, Kupari M, Kovanen PT: Complement system is activated in stenotic aortic valves, Atherosclerosis 2008, 196:190-200

6. Rajamannan NM, Subramaniam M, Springett M, Sebo TC, Niekrasz M, McConnell JP, Singh RJ, Stone NJ, Bonow RO, Spelsberg TC Atorvastatin inhibits hypercholesterolemia-induced cellular proliferation and bone matrix production in the rabbit aortic valve. Circulation 2002, 105:2660-2665

7. Poggianti E, Venneri L, Chubuchny V, Jambrik Z, Baroncini LA, 
Picano E: Aortic valve sclerosis is associated with systemic endothelial dysfunction. J Am Coll Cardiol 2003, 41:136-141

8. Chandra HR, Goldstein JA, Choudhary N, O'Neill CS, George PB, Gangasani SR, Cronin L, Marcovitz PA, Hauser AM, O'Neill WW: Adverse outcome in aortic sclerosis is associated with coronary artery disease and inflammation. J Am Coll Cardiol 2004, 43:169-175

9. Agmon Y, Khandheria BK, Jamil Tajik A, Seward JB, Sicks JD, Fought AJ, O'Fallon WM, Smith TF, Wiebers DO, Meissner I: Inflammation, infection, and aortic valve sclerosis; Insights from the Olmsted County (Minnesota) population. Atherosclerosis 2004, 174:337-342

10. Fox CS, Guo CY, Larson MG, Vasan RS, Parise H, O'Donnell CJ, D'Agostino RB, Sr., Keaney JF Jr, Benjamin EJ: Relations of inflammation and novel risk factors to valvular calcification. Am J Cardiol 2006, 97:1502-1505

11. Freeman RV, Otto CM: Spectrum of calcific aortic valve disease: pathogenesis, disease progression, and treatment strategies. Circulation 2005, 111:3316-3326

12. Taylor GA, Carballo E, Lee DM, Lai WS, Thompson MJ, Patel DD, Schenkman DI, Gilkeson GS, Broxmeyer HE, Haynes BF, Blackshear PJ: A pathogenetic role for TNF alpha in the syndrome of cachexia, arthritis, and autoimmunity resulting from tristetraprolin (TTP) deficiency. Immunity 1996, 4:445-454

13. Lai WS, Carballo E, Strum JR, Kennington EA, Phillips RS, Blackshear PJ: Evidence that tristetraprolin binds to AU-rich elements and promotes the deadenylation and destabilization of tumor necrosis factor alpha mRNA. Mol Cell Biol 1999, 19:4311-4323

14. Carballo E, Blackshear PJ: Roles of tumor necrosis factor-alpha receptor subtypes in the pathogenesis of the tristetraprolin-deficiency syndrome. Blood 2001, 98:2389-2395

15. Carballo E, Lai WS, Blackshear PJ: Feedback inhibition of macrophage tumor necrosis factor-alpha production by tristetraprolin. Science 1998, 281:1001-1005

16. Carballo E, Lai WS, Blackshear PJ: Evidence that tristetraprolin is a physiological regulator of granulocyte-macrophage colony-stimulating factor messenger RNA deadenylation and stability. Blood 2000, 95:1891-1899

17. Chen YL, Huang YL, Lin NY, Chen HC, Chiu WC, Chang CJ: Differential regulation of ARE-mediated TNFalpha and IL-1beta mRNA stability by lipopolysaccharide in RAW264.7 cells. Biochem Biophys Res Commun 2006, 346:160-168

18. Stoecklin G, Tenenbaum SA, Mayo T, Chittur SV, George AD, Baroni TE, Blackshear PJ, Anderson P: Genome-wide analysis identifies interleukin-10 mRNA as target of tristetraprolin. J Biol Chem 2008, 283:11689-11699

19. Lai WS, Parker JS, Grissom SF, Stumpo DJ, Blackshear PJ: Novel mRNA targets for tristetraprolin (TTP) identified by global analysis of stabilized transcripts in TTP-deficient fibroblasts. Mol Cell Biol 2006, 26:9196-9208

20. Datta S, Biswas R, Novotny M, Pavicic PG Jr, Herjan T, Mandal P, Hamilton TA: Tristetraprolin regulates CXCL1 (KC) mRNA stability. J Immunol 2008, 180:2545-2552

21. Saber AT, Jacobsen NR, Bornholdt J, Kjaer SL, Dybdahl M, Risom L, Loft S, Vogel U, Wallin H: Cytokine expression in mice exposed to diesel exhaust particles by inhalation. Role of tumor necrosis factor. Part Fibre Toxicol 2006, 3:4

22. Hirsch S, Gordon S: Polymorphic expression of a neutrophil differentiation antigen revealed by monoclonal antibody $7 / 4$. Immunogenetics 1983, 18:229-239

23. Rabinowitz SS, Gordon S: Macrosialin, a macrophage-restricted membrane sialoprotein differentially glycosylated in response to inflammatory stimuli. J Exp Med 1991, 174:827-836

24. Hughes DA, Gordon S: Expression and function of the type $3 \mathrm{com}-$ plement receptor in tissues of the developing mouse. $J$ Immunol 1998, 160:4543-4552

25. Martinez-Pomares L, Reid DM, Brown GD, Taylor PR, Stillion RJ, Linehan SA, Zamze S, Gordon S, Wong SY: Analysis of mannose receptor regulation by IL-4. IL-10, and proteolytic processing using novel monoclonal antibodies. J Leukoc Biol 2003, 73:604-613

26. van der Laan LJ, Kangas M, Dopp EA, Broug-Holub E, Elomaa O, Tryggvason K, Kraal G: Macrophage scavenger receptor MARCO: in vitro and in vivo regulation and involvement in the anti-bacterial host defense. Immunol Lett 1997, 57:203-208

27. Crocker PR, Gordon S: Mouse macrophage hemagglutinin (sheep eryth- rocyte receptor) with specificity for sialylated glycoconjugates characterized by a monoclonal antibody. J Exp Med 1989, 169:1333-1346

28. Ramprasad MP, Terpstra V, Kondratenko N, Quehenberger O, Steinberg D: Cell surface expression of mouse macrosialin and human CD68 and their role as macrophage receptors for oxidized low density lipoprotein. Proc Natl Acad Sci USA 1996, 93:14833-14838

29. Hayward MD, Jones BK, Saparov A, Hain HS, Trillat AC, Bunzel MM, Corona A, Li-Wang B, Strenkowski B, Giordano C, Shen H, Arcamone E, Weidlick J, Vilensky M, Tugusheva M, Felkner RH, Campbell W, Rao Y, Grass DS, Buiakova O: An extensive phenotypic characterization of the hTNFalpha transgenic mice. BMC Physiol 2007, 7:13

30. Petkova-Kirova PS, Gursoy E, Mehdi H, McTiernan CF, London B, Salama G: Electrical remodeling of cardiac myocytes from mice with heart failure due to the overexpression of tumor necrosis factor-alpha. Am J Physiol Heart Circ Physiol 2006, 290:H2098-H2107

31. Saba S, Janczewski AM, Baker LC, Shusterman V, Gursoy EC, Feldman AM, Salama G, McTiernan CF, London B: Atrial contractile dysfunction, fibrosis, and arrhythmias in a mouse model of cardiomyopathy secondary to cardiac-specific overexpression of tumor necrosis factor-\{alpha\}. Am J Physiol Heart Circ Physiol 2005, 289:H1456-H1467

32. Sivasubramanian N, Coker ML, Kurrelmeyer KM, MacLellan WR, DeMayo FJ, Spinale FG, Mann DL: Left ventricular remodeling in transgenic mice with cardiac restricted overexpression of tumor necrosis factor. Circulation 2001, 104:826-831

33. Engel D, Peshock R, Armstong RC, Sivasubramanian N, Mann DL: Cardiac myocyte apoptosis provokes adverse cardiac remodeling in transgenic mice with targeted TNF overexpression. Am J Physiol Heart Circ Physiol 2004, 287:H1303-H1311

34. Kontoyiannis D, Pasparakis M, Pizarro TT, Cominelli F, Kollias G: Impaired on/off regulation of TNF biosynthesis in mice lacking TNF AU-rich elements: implications for joint and gut-associated immunopathologies. Immunity 1999, 10:387-398

35. Cope AP, Liblau RS, Yang XD, Congia M, Laudanna C, Schreiber RD, Probert L, Kollias G, McDevitt HO: Chronic tumor necrosis factor alters $T$ cell responses by attenuating $T$ cell receptor signaling. J Exp Med 1997, 185:1573-1584

36. Lambin S, van Bree R, Vergote I, Verhaeghe J: Chronic tumor necrosis factor-alpha infusion in gravid C57BL6/J mice accelerates adipose tissue development in female offspring. J Soc Gynecol Investig 2006, 13:558-565

37. Li G, Barrett EJ, Barrett MO, Cao W, Liu Z: Tumor necrosis factoralpha induces insulin resistance in endothelial cells via a p38 mitogen-activated protein kinase-dependent pathway. Endocrinology 2007, 148:3356-3363

38. Iha H, Peloponese JM, Verstrepen L, Zapart G, Ikeda F, Smith CD, Starost MF, Yedavalli V, Heyninck K, Dikic I, Beyaert R, Jeang KT: Inflammatory cardiac valvulitis in TAX1BP1-deficient mice through selective NF-kappaB activation. EMBO J 2008, 27:629-641

39. Amigo MC: The heart and APS. Clin Rev Allergy Immunol 2007 32:178-183

40. Colao A, Spinelli L, Marzullo P, Pivonello R, Petretta M, Di Somma C, Vitale G. Bonaduce D, Lombardi G: High prevalence of cardiac valve disease in acromegaly: an observational, analytical, case-control study. J Clin Endocrinol Metab 2003, 88:3196-3201

41. Burns JC, Mason WH, Hauger SB, Janai H, Bastian JF, Wohrley JD, Balfour I, Shen CA, Michel ED, Shulman ST, Melish ME: Infliximab treatment for refractory Kawasaki syndrome. J Pediatr 2005, 146: 662-667

42. Edrees AF, Misra SN, Abdou NI: Anti-tumor necrosis factor (TNF) therapy in rheumatoid arthritis: correlation of TNF-alpha serum level with clinical response and benefit from changing dose or frequency of infliximab infusions. Clin Exp Rheumatol 2005, 23:469-474

43. Lamprecht $\mathrm{P}$, Voswinkel J, Lilienthal T, Nolle B, Heller M, Gross WL, Gause A: Effectiveness of TNF-alpha blockade with infliximab in refractory Wegener's granulomatosis. Rheumatology (Oxford) 2002, 41:1303-1307

44. Sfikakis PP, Markomichelakis N, Alpsoy E, Assaad-Khalil S, Bodaghi B, Gul A, Ohno S, Pipitone N, Schirmer M, Stanford M, Wechsler B, Zouboulis $\mathrm{C}$, Kaklamanis $\mathrm{P}$, Yazici $\mathrm{H}$ : Anti-TNF therapy in the management of Behcet's disease-review and basis for recommendations. Rheumatology (Oxford) 2007, 46:736-741

45. Guilherme L, Fae KC, Oshiro SE, Tanaka AC, Pomerantzeff PM, Kalil $\mathrm{J}$ : Rheumatic fever: how S. pyogenes-primed peripheral T cells trigger heart valve lesions. Ann NY Acad Sci 2005, 1051:132-140 
46. Quinn A, Kosanke S, Fischetti VA, Factor SM, Cunningham MW Induction of autoimmune valvular heart disease by recombinant streptococcal m protein. Infect Immun 2001, 69:4072-4078

47. Pena JM, Garcia-Alegria J, Garcia-Fernandez F, Arnalich F, Barbado FJ, Vazquez JJ: Mitral and aortic regurgitation in Behcet's syndrome. Ann Rheum Dis 1985, 44:637-639

48. Burdick S, Tresch DD, Komokowski RA: Cardiac valvular dysfunction associated with Crohn's disease in the absence of ankylosing spondylitis. Am Heart J 1989, 118:174-176

49. Fukunaga S, Egashira A, Arinaga K, Akasu I, Kai E, Higashi T, Kosuga K, Aoyagi S, Kazue T: Aortic valve replacement for aortic regurgitation due to Kawasaki disease. Report of two cases. J Heart Valve Dis 1996, 5:231-234

50. Oliveira GH, Seward JB, Tsang TS, Specks U: Echocardiographic findings in patients with Wegener granulomatosis. Mayo Clin Proc 2005, 80:1435-1440

51. Misukiewicz P, Carlson RW, Rowan L, Levitt N, Rudnick C, Desai T:
Acute aortic insufficiency in a patient with presumed Reiter's syndrome. Ann Rheum Dis 1992, 51:686-687

52. Podell TE, Wallace DJ, Fishbein MC, Bransford K, Klinenberg JR Levine S: Severe giant cell valvulitis in a patient with Reiter's syndrome. Arthritis Rheum 1982, 25:232-234

53. Iveson JM, Thadani U, Ionescu M, Wright V: Aortic valve incompetence and replacement in rheumatoid arthritis. Ann Rheum Dis 1975 34:312-320

54. Hayashi I, Hosoda Y, Kawasaki S, Yamamoto T, Dohi S, Kawai S: Aortic and mitral valve replacement in a patient with acute febrile neutrophilic dermatosis (Sweet's syndrome): report of a case. Surg Today 2001, 31:810-813

55. Guilherme L, Cunha-Neto E, Coelho V, Snitcowsky R, Pomerantzeff PM, Assis RV, Pedra F, Neumann J, Goldberg A, Patarroyo ME, Pileggi F, Kalil J: Human heart-infiltrating T-cell clones from rheumatic heart disease patients recognize both streptococcal and cardiac proteins. Circulation 1995, 92:415-420 